\title{
Implementing Adaptive e-Learning Conceptual Model: A Survey and Comparison with Open Source LMS
}

\author{
https://doi.org/10.3991/ijet.v14i21.11030 \\ Abdalla Alameen ${ }^{(\bowtie)}$, Bhawna Dhupia \\ University of Prince Sattam bin AbdulAziz, Al-Kharj, KSA \\ a.alameen@psau.edu.sa
}

\begin{abstract}
This paper deals with the necessary steps to be followed in upgrading the traditional e-Learning system to the new Adaptive e-Learning system. The framework, which is an important part of the implementation, is also covered in the paper. Before implementing the adaptive learning system, the existing system needs to be reviewed. A survey was conducted to find practical feedback from both the users: students and instructors to recognize their belief about the current e-Learning system. Results are discussed to frame the strategy to implement an adaptive learning system in which the issues of the current system can be addressed. To confirm the feedback, a report from the university LMS has also been taken into account and talked about. There are many open sources available in the market for the implementation of the adaptive e-learning. Along with the conceptual model, various popular LMS has also been discussed. A detailed comparison has also been exercised to identify their features. This paper can help the readers to derive all the components of a conceptual model for an adaptive e-Learning system and choose a suitable LMS for the actual implementation of the model.
\end{abstract}

Keywords-Adaptive learning system, conceptual framework, e-learning

\section{Introduction}

In the contemporary world, the learning paradigm has changed given the varied dynamics and increased popularity of technology [1]. Accepting the individuality of the individuals, efforts are being made for catering to the diversified need of the learners for enhancing their competence [2]. Educational practices have been significantly affected due to the growth in the applied science. The advent of the internet has stimulated the learning practices and provided various mediums and applications to cater the student's educational needs. E-learning is one such practice which use has escalated given the globalization of the world. This is evident from the enrolment of over 6 million students in the online courses offered as of 2018 [3]. Elearning uses a web-based instructional system which delivers the learning material learners. Many applications are available on the internet; however, they only deliver HTML pages and overlook the concept of a cognitive aspect of each scholar [4]. Various mode of e-learning education is adopted by users targeting towards their 
achievement of determined learning goals. The material provided in e-learning is not comprehensive enough to solve the problem of all the users due to the common syllabus and common monotonous learning styles. Therefore, the modern education system is approaching towards adaptive e-learning method to fill the gap of conceptual knowledge [5].

Adaptive e-learning system (AES) has come to the fore in the last ten years. This elearning system is a more efficacious and efficient web-based intelligent way of delivering the training online [5-6]. The AES system offers is an alternative learning solution which provides various services to adapt based on the learner's profile. The AES is based on the user model, which gathers information about the users, their goals of learning, learning pattern, knowledge level, and their aptitude. Subsequent to processing of this information, it offers the best suitable style of learning to the learners [7]. The AES is an intelligent system to accommodate the reading style of users and Web-Based Instruction (WBI), which is the combination of sound, picture, graphics, plain text and hyperlinks known as hypermedia to provide relevant learning environment on the courses offered [8]. Adaptive learning is based on the hypothesis that the identification of learning style is an integral tool to improve the individual learning of a learner, especially in e-learning. In this system, learners expect to have a unique style of teaching that helps achieve the learning goal. In addition, AES allows the users to not only opt their choices of instruction but also offer them the opportunities to use other resources available in the web [6].

To implement a web-based learning system, an LMS (Learning Management System) is demanded [6]. LMS is a software tool which enables learners and instructors to perform activities of sharing course material, holding an examination, making a class announcement, generating grade cards, making interactive communication, etc. [10]. LMS is used by universities, organizations, cooperation, and governments to impart training using online mode. There are many e-learning tools available in the market to offer various training. The decision of choosing an LMS for imparting training affects the quality of training and cost of implementation for the organization. There are some LMSs with the license fee and some are an open sources system available for educational research use. The organization before making any decision on this should consider all the aspects for choosing an LMS. An LMS must be evaluated first on the basis of usage capacity, budget and objective of the training.

Anecdotal studies have been found stressing over the instigation of the adaptive learning system for bridging the gap that prevails in the online learning of the learners. Most of the earlier studies highlight three aspects inclusive of authorizing of the content, pedagogical concerns, and modeling of the approaches adopted by users. The authorizing of the content is reflected as an essential tool for the application of certain specialized software that arranges and aligns the content for learning. AMAS, MOT, TANGOW, AHA, and GRAPPLE are some of the tools utilized for this purpose [10]. This variety of tools vary in terms of their nature which serves as a great benefit though it requires in-depth analysis of its assessment and evaluation practices for making the right selection. The main challenge faced is the matching of the subject domain with the need of the particular group of learners. The technicality of 
some of these tools makes it more difficult for users [11]. The pedagogical issues of the authorization of these serve as another hindrance for its implementation [12]. The variety of pedagogical tools and rule in the adaptive learning vary based on the policies of the institution, study domain as well as criteria for assessment [13].

A predefined learning program may serve as a hindering block for many users based on the diversified need, which requires the formulation of a generalized system which can be modelled or adapted to the institution practices. Moreover, the modelling of the user practices is also a prime consideration of the researches, where the two models, one based on knowledge and other on behavior are supplemented [14]. The application of approaches allows devising the adaptation rules which produces adaptive content. In the knowledge-based system, the user profile, preferences and learning styles are assessed for gathering structured and unstructured information [15]. Whereas, behavior approaches study the behavior of the learner during his interaction with the system [10].

Though, the integration of two has observed to be lacking. The paucity of information has emphasized the current study to adopt both of these techniques for formulating an adaptive e-learning system. For this, the study has performed a survey of the university students. The generated feedback is used for the construction of the new system to bridge the learning gap which prevails in the current system. Comparability of the analysis is executed with the actual report processed by the current e-Learning system of the university. Along with it, it also proposes a conceptual model for implementation of the new adaptive learning model in the university based on IEEE learning technology system architecture (LTSA) reference model. For the actual implementation of the conceptual model, the review is done on the LMSs available in the market. It presents a glimpse of the features available in various LMSs. For clear and concise information comparative results are exhibited in a tabular format. Since there are many open source Learning Management Systems (LMS) available in the market. A review and comparison of most popular LMS tools have also been conducted to choose the best option for actual implementation.

\section{Methodology}

\subsection{Study design}

In the research, the quantitative design is employed for understanding the elearning needs of the students based on which an adaptive learning system is proposed. Since the primary objective of this paper is to study and evaluate the existing e-learning system in order to design a new model based on adaptive elearning environment. Before proposing an adaptable solution for adaptive e-Learning implementation, review of the existing system has been done. Based on the result, a new conceptual model is proposed for the adaptive framework. 


\subsection{Study sample}

The target group includes students and faculties who are users of the e-Learning system namely, Blackboard (BB) offered by the university. A total of 167 students (male and female) has been recruited for the study from the College of Arts \& Science University from the Departments of Computer Science, Physics, Mathematics, and English. Along with it, a survey of 47 teachers was also conducted in various departments of the university. The understanding of the current e-learning system and its concerns serve as a base for this research work.

\subsection{Data collection}

The study started with the valuation of the existing system. For this, a questionnaire-based survey was conducted of the students using the paper method. Though there are various methods which can be adopted for the existing system review such as interview, online feedback, discussion forums, paper feedback, etc. However, the target user interest and technical issues affect the gathering of the data using online feedback or filling the feedback form, which can be overcome using the stated method. The questions were related to the working experience of the users. Two separate questionnaires were prepared (one for the learner and other for the faculty members) where the items revolved around the current system such as its usability, benefits, and issues related to the performance of the existing application. The questionnaire was translated into the Arabic language for the purpose of comprehensibility and justified feedback from Arabic speakers.

\subsection{Research instrument}

The questionnaire for the learner contained 12 questions which were prepared after reviewing various studies to capture the feedback about the current e-Learning systems by other researchers. Whereas, the questionnaire given to the faculty members was inclusive of questions related to the material used by them for imparting the e-learning module such as audio, videos, text, etc. to the students. It also contains the question regarding the facilities used by them in e-learning system like chatting, discussion room, video lectures to make connecting with the students, the training and technical support provided to them to use the e-learning system. Subsequent sections show the result of the survey conducted. This result will guide us to plan a model for our project and understand the issues in the current system.

\subsection{Data assessment}

The data gathered from the students and teaching faculty was analyzed using SPSS Version 23.0. The dataset collected from the survey was arranged in two excel sheet for the elaborative analysis. The processed data was exhibited in tabular format which makes its comprehension and understanding easy. 


\section{Results and Discussion}

Prior to the dissemination of the questionnaire, the co-efficient reliability of the questionnaires was checked using Cronbach Alpha. The Cronbach's Alpha value achieved was $86 \%$ which was substantially high and indicated towards the increased reliability of the questionnaire [16]. The initial four questions in the learner's questionnaire revolved around the current system accessibility and use of the internet facility for the students at home and in college. The evaluation of the student's responses provides that the availability of internet connection in the campus was not adequate. $52 \%$ of the students voted that they do not have a quality internet facility on campus. Question 4 was related to the time spent on the e-learning website. According to a percentage of $64.6 \%$, the students had that less than an hour to spend on the e-learning website. The analysis is shown in Figure 1.

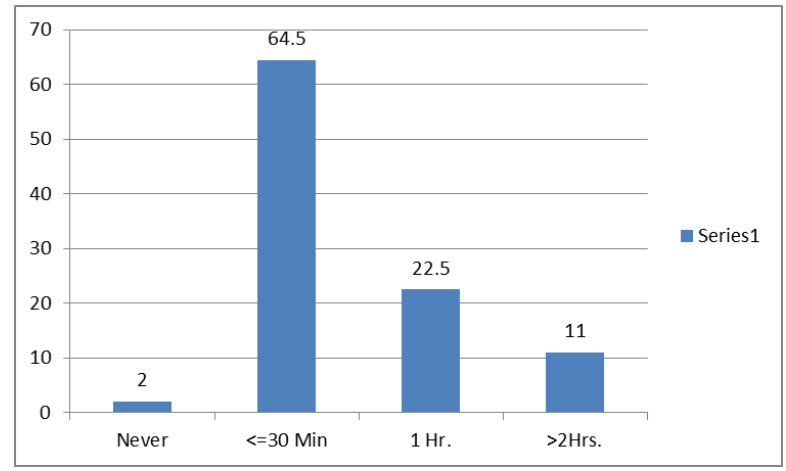

Fig. 1. eLearning App Usability Status - Time Spent on Tool

It is observed that majority of the students use e-Learning tool for accessing the text notes from the website, which consumes a maximum of 30 minutes to download. From the responses of the students, it is observed that there were few students who were not using the tool at all. Most of the students responded that they just needed to download the course material from the website. There is nothing else interesting on the site which can help them to understand the course. This can be verified by the analysis of the faculty feedback form in Figure 2, where the e-learning website is being merely used to upload the text related to course and assignment. 


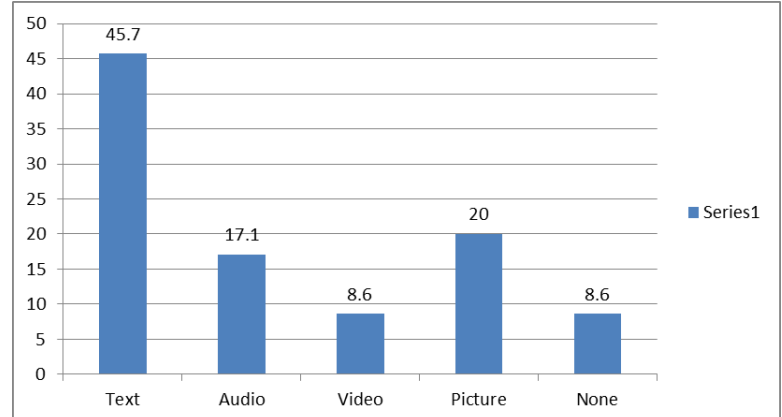

Fig. 2. eLearning App Usability Status - Types of eLearning Material Shared by the faculty

The second questionnaire was related to the faculty members' feedback regarding the e-learning system currently being employed by the university. The questionnaire reliability of this feedback form was found to be $79 \%$, according to the Cronbach's Alpha. This questionnaire deals with the type of course material used by the faculty members to distribute the learning material. The categories of material to distribute the learning material are listed such as audio, video, pictures, and text. The responses of the teaching faculty are comprehensively exhibited in figure 2 . It is noticed that the maximum percentage of the course material was text, which includes notes, books etc. Some faculties also used audios and videos, but the percentage of the usage was quite low. The 3rd question deals with the facilities they use to impart the training. The relationship between question 2 and 3 indicates that the faculties were using the elearning system only for distributing their notes and assignments and most of the other facilities were not being fully utilized.

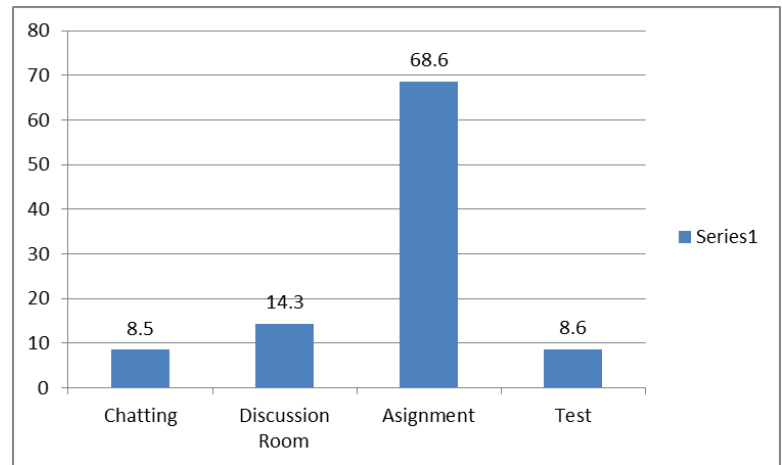

Fig. 3. eLearning App Usability Status - Facility of Communication Used by the faculty

The Figure-3 is giving concise details about the facilities being used for the elearning course. From this table and graph, it is quite clear that $68 \%$ of the faculties was using e-learning website to pass the assignment to the students and other interactive facilities like chatting, discussion room and the test was being used i.e. $8.6 \%, 14.3 \%$, and $8.6 \%$ respectively. The large extent use of the facilities for the 
formulation of the interesting session was not being utilized. Question 5, 6 and 7 were related to the support and training provided by the university, where a positive percentage is observed. The facilities provided by the University e-learning Related Issues and training were appreciating and convenient.

After analyzing both the results of feedback, it can be concluded that the faculties used the e-learning for just delivering the course material. This practice makes the system monotonous and the students are unable to develop their interest for the utilization of the e-learning system in their learning endeavors. The students simply $\log$ on to the system and download their lecture material; whereas, the main task of the e-learning education is to make the learning more interactive and interesting. The Adaptive learning technology has the potential to serve the purpose of providing a meaningful learning experience which takes care of the individual learning after analyzing the learning style of the learner.

The result from the survey has provided a glimpse of the existing system. The LMS is used currently is BB. This is one of the best LMSs available. But, as per the mentioned result, it is evident that the system is not being utilized to its fullest. Given the commercial use of the BB as an LMS, an organization has to invest a huge amount of money for its utilization. Considering this, the study concentrates on the open source LMS tools with integrates into features similar to BB. The smooth transition for the organization from BB to some other LMS is expected which also serves to be free of cost. This also allows the university to reduce the cost of e-learning module implementation for the students. The objective of this paper is to design and implement adaptive e-Learning model and suggest an open source LMS for the implementation. As Adaptive e-Learning is the extension of traditional e-Learning model, e-learning application architecture can help to design an adaptive e-learning system. Before moving to the model design for adaptive e-learning, subsequent sections will provide a brief introduction of the IEEE LTSA reference model [17]. This model is adopted as the base for the proposed model of the project.

To support the above discussion and analysis driven by the processing of feedbacks taken from the students and faculties, the semester reports from the BB software of the university are given below. This shows the details of facilities used by the faculty members to deliver the e-learning.

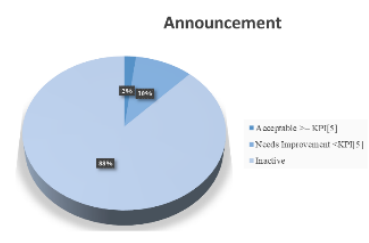

(a)

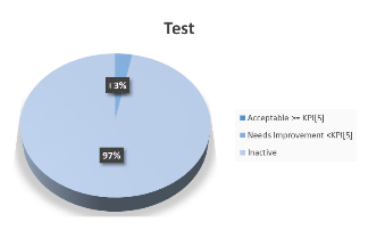

(b)

Fig. 4. Facility usage (Announcement \& Assignment)

Figure 4(a) clearly shows that the facility use of the system for the announcement is $12 \%$ only. Out of which, $10 \%$ needs improvement in its usage and $2 \%$ usage is inadequate. In the same way, the assignment feature is highlighted in Figure 4(b) 
which is certainly a very important feature to know the learning outcome of the students. The percent of acceptable usage is $5.1 \%$, which is really low.
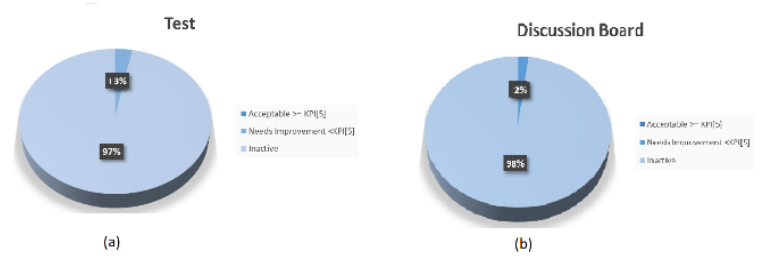

Fig. 5. Facility usage (Tests \& Discussion Boards)

Figure 5(a) shows the detailed usage percentage of the test, which describes that less than $4 \%$ utility is being utilized and that too needs improvement. Same is the case with the discussion board facility shown in Figure 5(b). It is being used by only $2 \%$ and requires improvement.

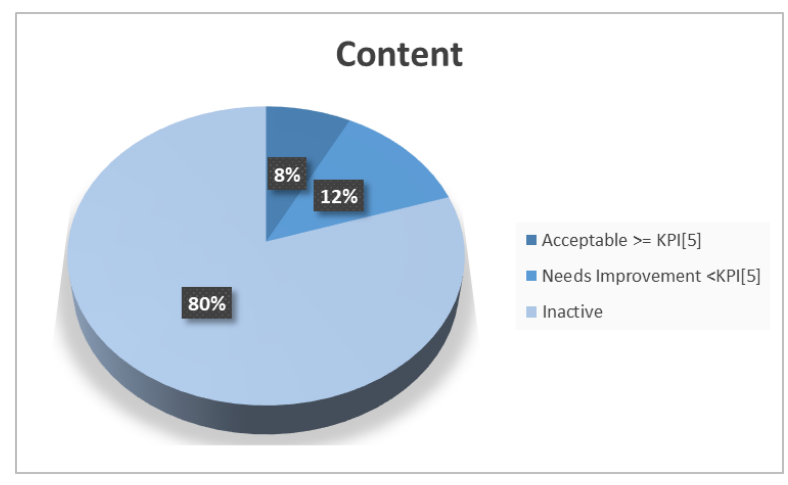

Fig. 6. Facility usage (Content)

Content facility usage is shown in Figure 6. This utility of the LMS uses $20 \%$ of the users, although the satisfactory usage of the utility is only $7.6 \%$. As discussed in the feedback result also, it is the maximum use of the facility by the users. From the above comparison between the feedback and actual data usage from the university dashboard, it is quite evident that the LMS implemented in the university is not being utilized to an optimum level. Keeping this analysis in mind, a new conceptual model is proposed. This model will include user-friendly tools to facilitate the use of LMS to an extent of satisfaction for all the users.

\section{IEEE LTSA Reference Model}

Based on [17], there is a reference model developed by the IEEE for the learning technology system architecture (LTSA). The study proposed architecture will be based on the IEEE (LTSA) for implementation of Adaptive e-Learning course. This 
model was initially prepared for implementation of the e-Learning. As Adaptive elearning is becoming an integral technology of e-Learning, this architecture serves as a solid guideline to put through the Adaptive e-Learning. To give a brief introduction of the implementation, this section gives a view of the IEEE LTSA conceptual model.

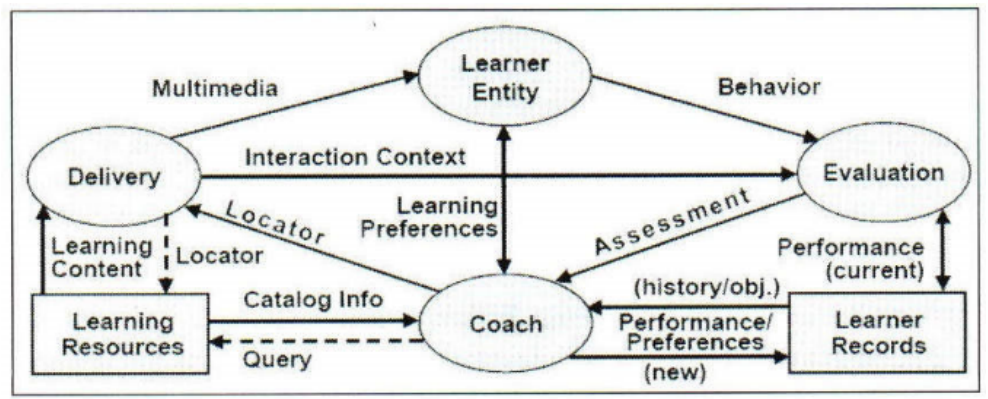

Fig. 7. The conceptual model of IEEE LTSA

Figure 7 shows the conceptual model designed by IEEE LTSA, which is the layer 3 of the complete LTSA model [18]. The ovals represent entities, boxes represent repositories, and dash arrow shows reflect control flows and solid arrows represents data flows. Upon the analyses of the model, there are two stores learning resources and learner records. Learning resource contains tutorials, various tools, experiments and other learning resources for the courses. Learner records stores information about the students, their past details and present working behavior. Along with it, the model comprises four processing entities. The first processing entity is learned, which can be an individual learner or group of learners related to a specific category. It receives the material from the teacher and guidance from the system coach. Coach is responsible to track the learning preference of the learner like learning style, learning strategy. This can be further modified offering the adaptive e-learning material to implement the individualized learning. Delivery entity interacts with the system coach and gets the learning resource for learning resources and distributes the material to the users. Finally, an evaluation entity analyses the behavior of the learner and evaluates their performance. The performance evaluated by the evaluation entity is saved in the record database for future reference $[17,19]$.

\section{Proposed Adaptive e-Learning Conceptual Model}

The proposed model for the project is based on the IEEE LTSA model. Figure 8 illustrates the interaction of the learners and the teacher with the system. This model primarily comprises of three modules, namely; Learner Module, Adaptation Module, and Teacher Module. A detailed description of these three modules and their interaction with the system is as follows. 


\subsection{Learner module}

Learner module deals with the learner i.e. his interaction with the system. Initially, students will get registered. In this step, learners input their demographic data, the objective of learning and the level of knowledge. To evaluate the knowledge and learning style of the learner, a questionnaire is provided to them. There are various styles discovered by many researchers for learning. One of the theories used in research to identify the learning style is Sarasin Model [20]. This model classifies learners into three main categories, namely, visual learner, an auditory learner, and kinesthetic learner. Based on three basic learning styles, the administrator will categorize the students to offer a suitable learning path. Depending on the analysis of the questionnaire filled by the learner, user modelling will be done.

\subsection{Adaptation module}

This module is one of the crucial parts for implementation of the adaptive model. Processing in this module will include the following steps.

- Step 1: Analyze the requirement of the learner along with the preferred learning pattern.

- Step 2: Provide two types of learning resources; adaptive and non-adaptive. Nonadaptive learning material will be common to all the learners. Adaptive learning material will be assigned to specific learners according to their learning preferences.

- Step 3: Record the user's activity and behavior to analyze the user's progress.

- Step 4: Evaluation of learner activities like assignments, quizzes, group discussion activity to evaluate their learning outcome.

- Step 5: This step will collect the feedback from the learners. The feedback will be related to learning facilities provided.

Data from step 3, 4 and 5 will get stored in the analyses engine to generate reports for each learner. The teacher will review the result to see the progress of the learner. The learning pattern will also analyze to see any change. If any change found, the new learning path will be assigned to the user model and sent to the adaptation model to follow the steps again. These steps keep on repeating until the course is completed. 


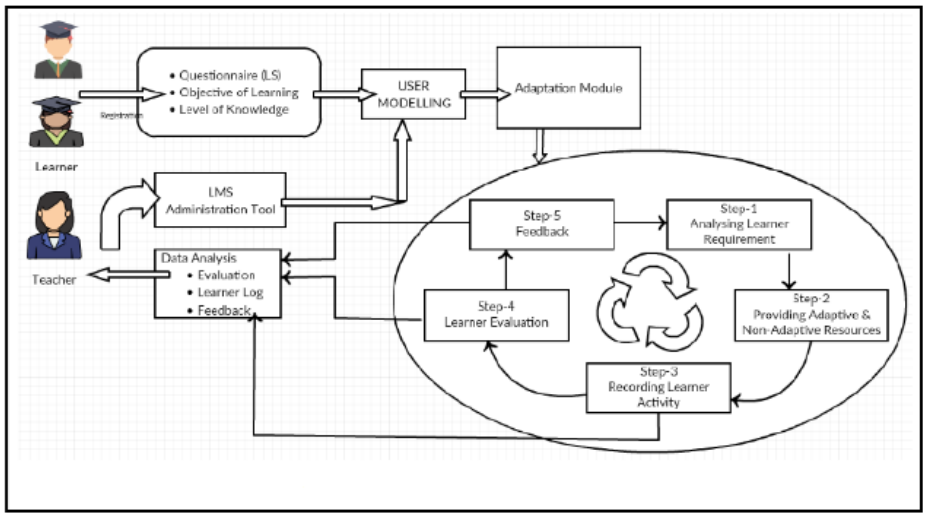

Fig. 8. Proposed Conceptual Model

\subsection{Teacher model}

All the activities of the learner are stored in a database as a log file. The log file for individual users will get analyzed to produce the report related to the evolution of the learner, their feedback and most importantly, their learning activities to see any change in their learning style. These reports will be sent to the teacher to review and modify the course strategy or learning path if required. This task is the major responsibility of the Teacher Model. Administration of the e-Learning tool will also be under the supervision of the teacher. They can do any modification in their respective subjects. At that point, users are allowed to access the non-adaptive resources and adaptive resources assigned to particular users. During the learning process, many activities are offered to users such as assignment, quizzes, presentation. These data will be recorded in the log files of each user. After a specific time, the data will get processed and be redirected to the course teacher for a review. If teachers find any change in the learning pattern of the user, a new learning style is assigned to them.

\section{$6 \quad$ LMS Implementation Tools}

Choosing the right LMS tool is one of the important decisions of the organization. For the successful implementation of the new model, it is very important to choose the best tool. There are many tools available in the market for the implementation of the adaptive e-learning framework. In this section, the study related to LMS tools will be done. This can guide us to choose the LMS for the project implementation. Figure 9 shows the most popular LMS tools based on the numbers of users, customers and social presence [21]. 


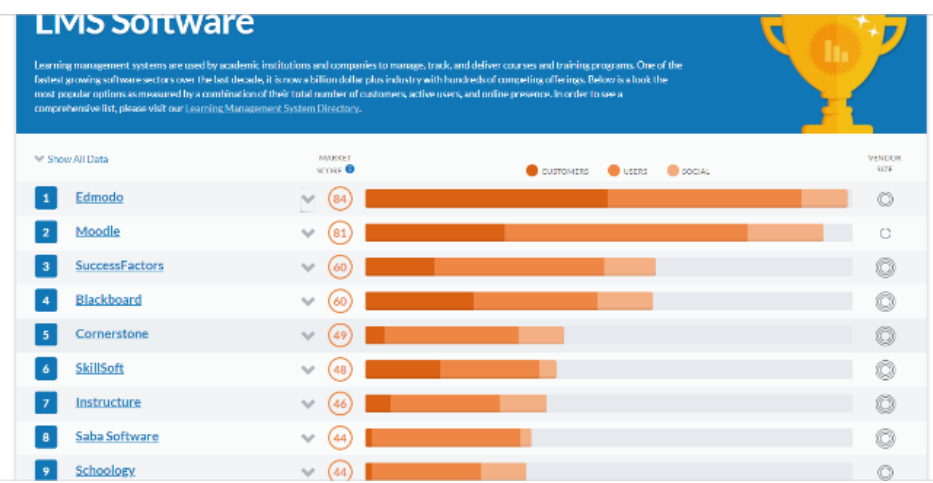

Fig. 9. Top LMS software March [2018]

For the survey purpose, the research has chosen five most popular LMS tools, namely; Moodle, EduBrite, TalentLMS, Edomodo, and Sakai. This section summarizes the tools with a brief description in terms of their features and usability.

\subsection{Moodle}

Moodle (Modular Object-Oriented Dynamic Learning Environment) is one of the well-known tools for LMS to implement constructive learning. Established in 2002 in Australia, it is positioned among the top five LMS tools worldwide [18]. At the moment, it provides support to 97,000 million sites with 130 million users in 231 countries [22]. It is designed to support both teaching and learning framework. The latest version of Moodle supports 120 languages. It is easily customizable as per the demand of the users. It also offers built-in plug-ins for effective implementation adaptive learning. The developer can choose from the list of plug-ins available and they can even program new plugin if required. It guides the users starting from the installation process till the code generation with the help of detailed documentation and videos.

\subsection{EduBrite}

EduBrite is an LMS for businesses and training providers. Users can create the customize course by adding existing resources for learning like text, audio, videos, and links to external sources. It supports 12 languages, including English, Arabic, Chinese and Dutch. Reports and analysis feature are also available in EduBrite to track the activities of the users and to generate reports. The software can integrate with other programs like Google Map, Google Analytics, etc. It offers bi-directional integration with external systems for the smooth administration of the application. If users want to shift from one LMS to another, it provides an automatic transfer method with all the contents and data [23]. 


\subsection{TalentLMS}

TalentLMS is an LMS tool to support small organizations. It supports both course management and learning delivery. Developers can design a customizable learning path with blended learning. It supports video conferencing to facilitate distance education. It has an assessment engine also to evaluate the user activity and survey feedbacks. It also supports rich communication tools like video conferencing and discussion forums. It supports e-commerce, which enables the developer to sell their courses via subscription or on monthly payments [24].

\subsection{Edmodo}

This LMS tool is specially designed for education purpose. It offers a link of communication for students, teachers, and parents as well. Parents are provided with a link to their children. Although parents cannot see all the activities done by the children, they can track the progress of the student through grade cards [25]. It provides a comment section for the students to share their experiences. A global connection feature makes student interact and collaborate with them for various projects. This feature helps learners find new ideas and resources for their courses [26]. It is also integrated with Google Apps for Education and Microsoft office to support the learner activities.

\subsection{Sakai}

Sakai was released in 2005 and was developed by the collaboration of four US universities. It is an open source with advanced features supporting learning, teaching, and research. More than 350 universities worldwide are using this tool for delivering e-learning courses. It offers a simple and easy to use GUI for course administration and student management. The courses can be configured, implemented, managed and distributed for any purpose. In 2014, Sakai modified the tools with advanced technical facilities like data analytics, multiple paths for learning and virtual conferencing [27]. One of the strongest tools of Sakai is called Statistic. It helps the administrator or instructor to view the site's facilities usage and the user's activities. The Statistic tool gives a very detailed view of the resources used by the learner. This helps the instructor to improve the learning material for the courses [28]. In Table 1, a comparison on the above mentioned LMS tools has been done. The comparison included the essential features required for implementation of the best e-learning framework. 
Table 1. Comparison between popular LMS tools

\begin{tabular}{|l|c|c|c|c|c|}
\hline \multicolumn{1}{|c|}{ Tool } & Moodle & EduBrite & TalentLMS & Edmodo & Sakai \\
\hline $\begin{array}{l}\text { Target Customer } \\
\text { Size }\end{array}$ & $1000+$ & $2-1000+$ & $10-1000+$ & Not Provided & Not Provided \\
\hline Platform & $\begin{array}{c}\text { Cloud, Windows, } \\
\text { Apple }\end{array}$ & Cloud & Cloud & Cloud & $\begin{array}{c}\text { Cloud, } \\
\text { Windows }\end{array}$ \\
\hline Mobile & iOS, Android & iOS, Android & iOS, Android & iOS, Android & iOS, Android \\
\hline e-commerce & No & Yes & Yes & No & Yes \\
\hline $\begin{array}{l}\text { Videoconferenci } \\
\text { ng }\end{array}$ & Yes & Yes & Yes & No & Yes \\
\hline $\begin{array}{l}\text { Blended } \\
\text { Learning }\end{array}$ & Yes & Yes & Yes & No & Yes \\
\hline $\begin{array}{l}\text { Virtual } \\
\text { Classroom }\end{array}$ & Yes & Yes & Yes & No & No \\
\hline $\begin{array}{l}\text { Synchronous } \\
\text { Learning }\end{array}$ & Yes & Yes & Yes & No & No \\
\hline $\begin{array}{l}\text { Asynchronous } \\
\text { Learning }\end{array}$ & Yes & Yes & No & No & Yes \\
\hline Skill Tracking & & & No & Yes \\
\hline
\end{tabular}

Important features for the implementation of adaptive e-learning model are considered for the sake of comparison. After reviewing the above LMS tool, it was found that Moodle is the best option. All significant features needed for implementation of an effective LMS are present in it. Moodle supports Cloud, Windows and Apple platforms. Moodle is adopted by many organizations; hence a considerable measure of research work has already been executed and proven. It has a developer's forum to share experiences, problems, solutions, and innovations. These types of information serve as a guide for the project of new developers. Apart from all these features, it offers a wide range of plug-ins to customize the LMS according to the preference of the developer. It also offers developers the facility to program the new plugins which are not available. Moodle facilitates a sophisticated internal and external communication environment for its users. This feature of Moodle supports the exchange of files, discussion forums, real-time chat sessions, and other attachments. Communication facility in Moodle is very secure as it passes through various levels of authentication tools during transferring and receiving procedure of data. It uses the authentication tools such as Remote Authentication Dial in User Service RADIUS [28], Central Authentication Service CAS (Wong \& Looi, 2009), and Network News Transfer Protocol NNTP [29] to authenticate the user before giving them access to use the resources, to single login authentication and broadcasting of message authentication respectively.

The use of this LMS system has been endorsed by various studies based on its efficacy for advancing the evaluation method for teachers and learners both [3032].Such as [33] elucidated on the editors used for the e-learning portals which provide new ways for providing more variety and improving the models for the learning. Along with it, a reference model has also been devised by the European project Media site [34] in an effort to cater to distance learning. Though, the work of these researches seems to be incomplete considering the adaptive aspect. Based on 
this, the study has proposed a new system integrating new LMS modeling portrait. The system has an edge as it relies mainly on learning conception and learner's interaction. The study [35] has emphasized on the behavior and cognitive aspect of the learning indicating towards LSM. Ref [36] has also elucidated on the use of active pedagogies for improving the learner's e-learning experience.

\section{Conclusion}

This paper overviews adaptive e-learning in a university environment. It also presents the review of an LMS installed in a university along with its advantages and improvement areas. To gather the experience of the users with the current LMS, a survey was conducted. The data collected from this survey were processed with IBM SPSS tool. The output from the tool is shared and discussed in detail to gather the current situation of the LMS used in the university set up. To support the analysis result, the actual report from the university LMS usage is shared. The report shared is for a complete semester. While we compare the feedback analysis and actual report from the LMS, it was rather clear that the current LMS is not being utilized to its wide capability. A few facilities are being utilized by the administration. Later on, a new conceptual model is proposed based on IEEE adaptive learning reference model to design a new adaptive system for the university. All the components of the conceptual model are discussed in five steps to portray a clear picture of the design proposed. For the execution of the model proposed, an LMS is required.

There are many open source LMSs available in the market. Thus, it is really a crucial step to decide on to choose the perfect LMS. To understand the features and facilities offered by the LMS available, a study is conducted. Most popular five LMS tools were selected and a revaluation was done on them. For a better understanding of the reader, information is arranged in a form of table. It can assist the user to understand and choose the best LMS for them. After a brief review of the LMS available, it was found that the Moodle is one of the best alternatives to implement the conceptual model proposed. It is an open source and has all the important features to implement an adaptive learning environment. Further, this project aims at implementing the proposed model in Moodle LMS. This LMS will be used by a pilot batch to check the reliability of the implementation. On successful completion, it can be imposed for the university.

\section{Acknowledgement}

The authors are very thankful to all the associated personnel in any reference that contributed in/for the purpose of this research. 


\section{$9 \quad$ References}

[1] Akhavan, P., Teimuri, Z., Rajabion, L., \& Philsoophian, M. (2018). Knowledge management and adaptive e-learning: Iranian Schools Case Study. Paper presented at the Akhavan, Peyman, Teimori Motlagh, Zahra, Rajabion, Lila \& Maryam Philsoophian (2018), Knowledge Management and Adaptive E-Learning: Iranian Schools Case Study. The 19th European Conference on Knowledge Management (ECKM 2018), September, Italy. https://doi.org/10.1108/vjikms-08-2017-0051

[2] Rukanuddin, H. K., \& Asfia R. (2016). Knowledge of individual differences of the learners of the second language enriches second language teaching. Journal of Literature, Languages, and Linguistics, 19, 11-15.

[3] Consortium, O. L. (2018). New study: over six million students now enrolled in distance education.

[4] Fouad, K. M., Nagdy, N. M., \& Harb, H. M. (2013). Adaptive E-Learning System Based on Semantic Search and Recommendation in the Arab World Information Systems Applications in the Arab Education Sector (pp. 254-283): IGI Global. https://doi.org/10. 4018/978-1-4666-1984-5.ch018

[5] Kumar, S., Gankotiya, A. K., \& Dutta, K. (2011). A comparative study of moodle with other e-learning systems. Paper presented at the Electronics Computer Technology (ICECT), 2011 3rd International Conference on. https://doi.org/10.1109/icectech.2011. $\underline{5942032}$

[6] Brusilovsky, P. (2003). Developing adaptive educational hypermedia systems: From design models to authoring tools Authoring tools for advanced technology Learning Environments (pp. 377-409): Springer. https://doi.org/10.1007/978-94-017-0819-7 13

[7] Esichaikul, V., Lamnoi, S., \& Bechter, C. (2011). Student modelling in adaptive e-learning systems. Knowledge Management \& E-Learning: An International Journal, 3(3), 342-355. https://doi.org/10.34105/j.kmel.2011.03.025

[8] Khan, B. H. (1997). Web-based instruction: Educational Technology.

[9] Stash, N., \& De Bra, P. (2004). Incorporating cognitive styles in AHA! (the adaptive hypermedia architecture). Paper presented at the Proceedings of the IASTED International Conference Web-Based Education.

[10] Ahmed, M. U., Sangi, N. A., \& Mahmood, A. (2017). A Learner Model for Adaptable eLearning. interaction, 8(6).

[11] Vassileva, D., Bontchev, B., Chavkova, B., \& Mitev, V. (2009). Software construction of an authoring tool for adaptive e-learning platforms. Paper presented at the Informatics, (2009). BCI'09. Fourth Balkan Conference in. https://doi.org/10.1109/bci.2009.43

[12] Gynther, K. (2016). Design Framework for an Adaptive MOOC Enhanced by Blended Learning: Supplementary Training and Personalized Learning for Teacher Professional Development. Electronic Journal of e-Learning, 14(1), 15-30.

[13] Swertz, C., Schmölz, A., Forstner, A., Heberle, F., Henning, P. A., Streicher, A., . . \& Zander, S. (2013). A Pedagogical Ontology as a Playground in Adaptive Elearning Environments. Paper presented at the GI-Jahrestagung.

[14] Battou, A. (2017). Designing an Adaptive Learning System Based on a Balanced Combination of Agile Learner Design and Learner Centered Approach. American Scientific Research Journal for Engineering, Technology, and Sciences (ASRJETS), 37(1), 178-186.

[15] Bourkoukou, E., Bachari, El, \& Adnani, ME (2016). A Personalized ELearning Based on Recommender System. International Journal of Learning and Teaching, 2(2). https://doi. org/10.18178/ijlt.2.2.99-103 
[16] Cronbach, L. J. (1957). The two disciplines of scientific psychology. American psychologist, 12(11), 671. https://doi.org/10.1037/h0043943

[17] Devedzic, V., Jovanovic, J., \& Gasevic, D. (2007). The pragmatics of current e-learning standards. IEEE Internet Computing, 11(3). https://doi.org/10.1109/mic.2007.73

[18] Fenton, W. (2016). The Best Learning Management Systems (LMS) for 2015.

[19] Soo, L. K., Yeoh, E.-T., \& Ho, S. B. (2011). A recommendation model for learning objects in a service-oriented e-learning environment. Paper presented at the IT in Medicine and Education (ITME), 2011 International Symposium on. https://doi.org/10.1109/itime.2011.6 $\underline{130751}$

[20] Sleigh. (2002). Learning Styles - from Theory to Practice. Training and Development in Australia. Australian Institute of Training and Development, 29(2).

[21] Capterra. (2018). Top LMS Software.

[22] Moodle. (2018). Moodle Statistics.

[23] Paunović V, P. S. \& Vasović, J. V. (2018). One MCDM Approach to Learning Management Systems Evaluation. 7th International Scientific Conference Technics and Informatics in Education., 238-243.

[24] Arora, D. (2018). Learning Management System (LMS) Using C\#, ASP. Net and SQL SERVER.

[25] Al-Said, K. M. (2015). Students' Perceptions of Edmodo and Mobile Learning and Their Real Barriers towards Them. Turkish Online Journal of Educational Technology-TOJET, 14(2), 167-180.

[26] Aaron. (2015). Introduction to Edmodo.

[27] Olajuwon, A. M. A. A. (2017). Interactive Adaptive Learning Management System (IALMS). International Journal of Scientific \& Engineering Research, 8(7).

[28] Wan, H., Yu, Q., Ding, J., \& Liu, K. (2017). Students' behavior analysis under the Sakai LMS. Paper presented at the Teaching, Assessment, and Learning for Engineering (TALE), 2017 IEEE 6th International Conference on. https://doi.org/10.1109/tale.2017.82 $\underline{52342}$

[29] Wong, L.-H., \& Looi, C.-K. (2009). Adaptable learning pathway generation with ant colony optimization. Journal of Educational Technology \& Society, 12(3).

[30] Benslimane, M., Zine, O., Derouich, A., \& Talbi, A. (2016). Proposition et implémentation sur moodle d'une approche de conception d'un cours en ligne: cas d'un cours d'algorithmique. Paper presented at the Workshop International sur les Approches Pédagogiques \& E-Learning. https://doi.org/10.3406/spira.2015.1737

[31] Chemsi, G, R. M., Sadiq, M, \& Talbi, M. (2011). Conception et validation d'un outil informatisé pour l'évaluation des enseignements et des formations à distance par les étudiants. EVAL-EFDE.

[32] Zoubaidi, X., Daoud, M. A., Namir, A., Talbi, M., \& Nachit, B. La formation de formateurs d'éducateurs du préscolaire: mise en place d'un dispositif de formation à distance. Revue de l'EPI, janv-2014. http://www. epi. asso. fr/revue/articles/a1401d. htm. https://doi.org/10.1016/j.revpod.2014.03.011

[33] Paquette, G. (2000). Construction de portails de télé-apprentissage. Sciences et Technologies de l'Information et de la Communication pour l'Éducation et la Formation, 7(1), 207-226. https://doi.org/10.3406/stice.2000.1451

[34] Bechina, A., Keith, B., \& Brinkschulte, U. (2001). Mediasite: Une nouvelle plate-forme dédiée à l'enseignement à distance: IRES.

[35] Chekour, M., Laafou, M., \& Janati-Idrissi, R. (2015). L'évolution des théories de l'apprentissage à l'ère du numérique. Revue de l'EPI (Enseignement Public et Informatique). 
[36] El Mhouti A, N. A., \& Erradi M. (2013). Les TIC au service d'un enseignementapprentissage socioconstructiviste. Revue de l'EPI (Enseignement Public et Informatique).

\section{Authors}

Abdalla Alameen received B.Sc. degree in computer science from International University of Africa, Sudan in 1997. He completed his M.Sc. in information technology from ALNeelain University, Sudan. He received his Ph.D. degree in Computer Science from Department of Computer Science and Information Technology at ALNeelain University, Sudan. Currently, he is working as HOD and Associate Professor at Computer Science Department, College of Arts and Science, Prince Sattam Bin Abdulaziz University, KSA. Alameen research interest includes information security, cloud computing, E -government, web application

Bhawna Dhupia received Bachelor in Computer Application degree and Masters in Computer Application in 2004 and 2009 respectively from IGNOU, India. Since September 2010 she has been working as a lecturer of computer science department in Prince Sattam bin Abdulaziz University, KSA. She has published papers in the field of mobile assisted learning, adaptive learning and security in cloud computing. Her research interest includes wireless sensor networks, mobile computing and cloud computing

Article submitted 2019-06-14. Resubmitted 2019-07-19. Final acceptance 2019-07-21. Final version published as submitted by the authors 